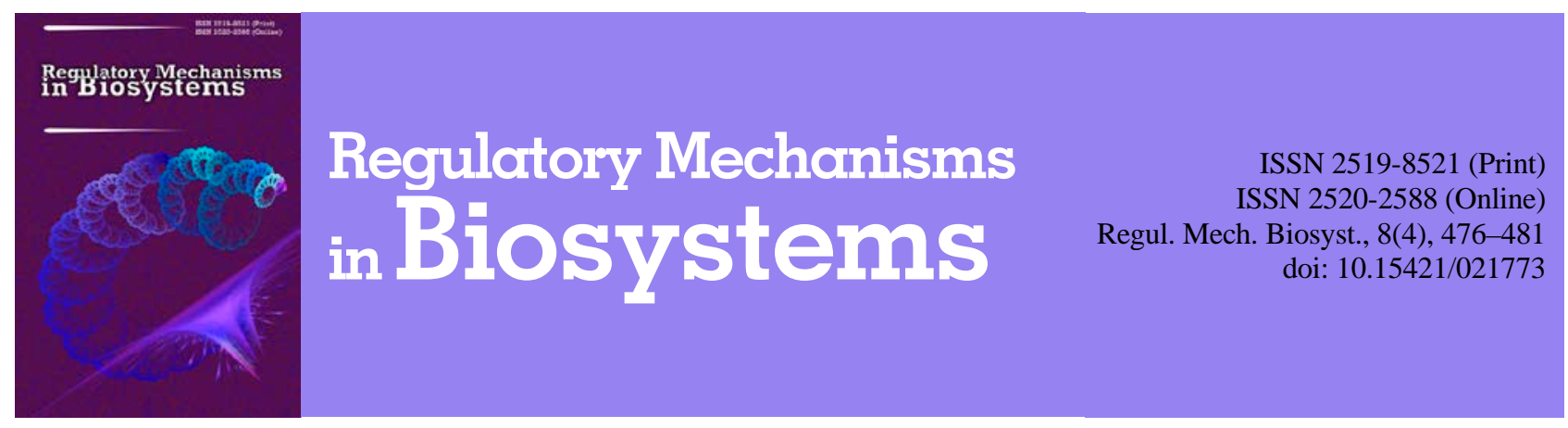

\title{
The reaction of immunophysiological parameters of carp yearlings (Cyprinus carpio) to intraperitoneal administration of Arochlore
}

\author{
T. B. Lapirova
}

\section{D. Papanin Institute for Biology of Inland Waters RAS, Borok, Russia}

\section{Article info}

Received 04.09.2017

Received in revised form 20.10.2017

Accepted 25.10.2017

I. D. Papanin Institute for Biology of Inland Waters RAS, Borok,

152742, Yaroslavl Oblast, Russia.

Tel.: +748-547-24-042

E-mail: ltb@ibiw.yaroslavl.ru

\begin{abstract}
Lapirova, T. B. (2017). The reaction of immunophysiological parameters of carp yearlings (Cyprinus carpio) to intraperitoneal administration of Arochlore. Regulatory Mechanisms in Biosystems, 8(4), 476-481. doi:10.15421/021773
\end{abstract}

Over 14 days we investigated the effect of a single intraperitoneal administration of Aroclor 1254, one of the most widespread mixtures of polychlorinated biphenyls, on the indexes of the spleen and liver, the level of hemoglobin and the total protein, glucose and circulating immune complexes of the blood serum of carp yearlings (Cyprinus carpio L.). The toxicant was dissolved in vegetable oil, to assess the effect of which the data of a separate group of fish were analyzed in addition to the intact control. It was shown that in both groups of fish injected, both with just oil and with Aroclor dissolved in oil, at the initial stages of the experiment, phase fluctuations of the majority of the investigated parameters were observed, as well as the growth of the individual variability of the indices in comparison with intact individuals. Analysis of the dynamics of change in the obtained data suggests that they are due to the administration of oil which can cause an inflammatory response (handling stress was minimized by anesthesia with MS-222 tricaine methanesulfonate). These changes are generally consistent with the pattern of total nonspecific stress reaction, the manifestations of which are smoothed out by the middle of the exposure. In the experimental group of fish, over these periods pronounced shifts of all indices were again recorded. This phenomenon suggests that during this period the concentration of toxic metabolites formed in the process of transformation of Aroclor reaches values that could significantly shift the homeostasis. This assumption is confirmed by the sharp increase on the 7-th day of the experiment of the content of immune complexes in the bloodstream. Changes by the end of exposure of all biochemical parameters, namely: an increase in the level of glycemia and decrease in the concentration of hemoglobin, serum protein and circulation of immune complexes, were statistically significant. The revealed changes indicate deviations in protein and carbohydrate metabolism and decrease in adaptive potential of fish caused by the toxicant. At the same time, the observed changes are most likely not irreversible and in the absence of further contact with the xenobiotic, the indices can return to normal.

Keywords: polychlorinated biphenyls; hemoglobin; serum; protein; glucose; the immune complexes

\section{Реакция иммунофизиологических показателей годовиков карпа (Cyprinus carpio) на внутрибрюшинное введение Арохлора}

\author{
Т. Б. Лапирова
}

Институт биологии внутренних вод имени И. Д. Папанина РАН, Борок, Россия

В течение 14 суток исследовали влияние однократного внутрибрюшинного введения Арохлора 1254, представляющего собой одну из наиболее широко распространенных смесей полихлорированных бифенилов, на индексы селезенки и печени, уровень гемоглобина и содержание общего белка, глюкозы и циркулирующих иммунных комплексов сыворотки крови годовиков карпа (Cyprinus carpio L.). Токсикант растворяли в растительном масле, для оценки влияния которого анализировали данные отдельной группы рыб помимо интактного контроля. У обеих групп рыб, получивших инъекцию, как отдельно масла, так и растворенного в нем Арохлора, на начальных этапах эксперимента наблюдали фазовые колебания большинства исследуемых параметров, а также рост индивидуальной изменчивости показателей по сравнению с интактными особями. Анализ динамики изменений полученных данных позволяет заключить, что они обусловлены введением масла, способного вызывать воспалительную реакцию (манипуляционный стресс минимизировали при помощи анестезии трикаинметансульфонатом MS-222). Эти изменения в целом соответствуют картине общей неспецифической стрессовой реакции, проявления которой сглаживаются к середине экспозиции. В опытной группе рыб в эти сроки вновь зафиксированы выраженные сдвиги всех показателей. Данное явление позволяет предположить, что в этот период концентрация токсичных метаболитов, образующихся в процессе трансформации Арохлора, достигает величин, способных заметно сдвинуть гомеостаз. Подтверждает это предположение и резкое увеличение на 7-е сутки эксперимента содержания в кровотоке иммунных комплексов. Изменения к концу экспозиции всех биохимических показателей (рост уровня гликемии и достоверное снижение концентрации гемоглобина, сывороточного 
белка и циркулирующих иммунных комплексов) были статистически значимы. Выявленные сдвиги указывают на отклонения в белковом и углеводном обмене и снижение адаптационного потенциала рыб, вызванные токсикантом. В то же время, обнаруженные изменения, скорее всего, не являются необратимыми и в случае отсутствия дальнейшего контакта с ксенобиотиком показатели могут вернуться к норме.

Ключевые слова: полихлорированные бифенилы; гемоглобин; сыворотка крови; белок; глюкоза; иммунные комплексы

\section{Введение}

Проблема антропогенного загрязнения окружающей среды не теряет своей актуальности на протяжении многих десятилетий. Наиболее устойчивые и высокотоксичные для организмов соединения объединены в группу стойких органических загрязнителей (СО3). В ряду прочих $\mathrm{CO} 3$ полихлорированнные бифенилы (ПХБ) занимают особое место, так как являются одними из самых распространенных и устойчивых (Gorbunova et al., 2011). Широкое применение ПХБ имели в качестве диэлектриков в трансформаторах и конденсаторах, входили в состав пластификаторов, красок, лаков, смазочных масел и пр. (Fedorov, 1993; Safe, 1994; Rodenburg et al., 2010). В 2001 году принята Стокгольмская конвенция, согласно которой предполагалось сокращение поступления в окружающую среду СО3, тем не менее, снижения уровня загрязнения пока не происходит.

В водные объекты ПХБ поступают в результате утечек из различных технических установок, прямого сброса с кораблей гидравлических жидкостей и смазок, а также вместе с пестицидами, содержащими ПХБ в качестве наполнителей (Moiseenko, 2009). Попав в водоем, эти соединения вызывают серьезные изменения в водных биоценозах, способны накапливаться в пищевой цепи (Quabius et al., 2002). Некоторые исследователи считают, что полициклические ароматические углеводороды и ПХБ присутствуют в природных водоемах повсеместно (Arruda et al., 2003).

В исследованиях по влиянию экотоксикантов на водные организмы особое место среди всех гидробионтов занимают рыбы. Это вызвано тем, что они являются вершиной пищевой цепи в водных экосистемах и при этом, по сравнению с высшими позвоночными, более чувствительны к изменениям среды, сдвиги показателей, например, неспецифического иммунитета, у них более быстрые и заметные (Alexander and Ingram, 1992). ПХБ способны вызывать значительные патологии тканей печени и селезенки рыб (Khan, 2003), нарушения репродуктивной системы (Barnthouse et al., 2009), оказывать иммуномодулирующий эффект и вызывать снижение общей резистентности (Arkoosh et al., 2001; Iwanowicz et al., 2009). Несмотря на то, что токсичность ПХБ и продуктов их трансформации исследуется уже в течение почти 50 лет, единого мнения относительно воздействия этих ксенобиотиков на рыб до сих пор нет (Henry, 2015), недостаточно данных по влиянию ПХБ на физиолого-биохимические показатели крови рыб.

Каждый из обычно применяемых в экспериментах способов введения в организм токсикантов имеет свои достоинства и недостатки. К преимуществам внутрибрюшинных инъекций относят возможность наиболее точно контролировать полученную животным дозу вещества: этот способ нередко используется в ихтиотоксикологии (O’Neil and Johnson, 2013).

Цель статьи - оценить влияние однократного внутрибрюшинного введения Арохлора 1254 на иммунофизиологические показатели крови карпа. В задачи исследования входило определение индексов селезенки и печени, анализ концентрации гемоглобина в периферической крови, а также общего белка, уровня гликемии и содержания циркулирующих иммунных комплексов в сыворотке в течение 14 суток.

\section{Материал и методы исследований}

Эксперимент проводили на годовиках карпа обыкновенного (Cyprinus carpio L.), выращенного на стационаре экспериментальных полевых работ «Сунога» ИБВВ РАН. Во время акклимации (21 сут.) и далее в течение эксперимента (14 сут.) подопытные рыбы находились в проточных аэрируемых аква- риумах объемом 150 л, ежедневно получая корм. В качестве токсического агента использовали промышленный препарат Arochlor 1254 (Monsanto Company, США). Химический состав серии Arochlor обозначается четырехзначным кодом, в котором первые две цифры относятся к числу атомов углерода фенильных колец, а последующие две указывают процент содержания хлора по массе (Pääkkönen et al., 2005). Препарат растворяли в прокаленном растительном масле.

Подопытные животные поделены на три группы: I - контрольная группа (интактные особи), II - контроль растворителя (рыбам вводили внутрибрюшинно 1 мл масла), III - опытная группа (рыбы получили инъекцию арохлора, растворенного в 1 мл масла, в дозе 200 мг/кг массы тела). Пробы отбирали у интактного контроля через 1,7 и 14 суток; у рыб II и III групп - через 1, 3, 7, 10 и 14 суток с начала эксперимента, в двух повторностях. При проведении инъекций применяли трикаинметансульфонат (MS-222) для анестезии. На точку отбирали по 5 рыб, средние длина и масса подопытных животных составили $178,7 \pm 18,8$ мм и $149,6 \pm 42,8$ г соответственно.

Индексы рассчитывали как отношение массы селезенки и печени к массе тела без внутренних органов (\%). Кровь отбирали после каудэктомии, часть ее стабилизировали гепарином и использовали для определения гемоглобина, из оставшейся получали сыворотку. Концентрацию гемоглобина анализировали на гемоглобинометре ГФП-01 МиниГЕМ+ гемихромным методом, глюкозы - глюкозооксидазным. Содержание общего белка сыворотки определяли по Bradford (1976), уровень циркулирующих иммунных комплексов (ЦИК) - стандартным методом путем осаждения с полиэтиленгликолем (Grinevich and Alferov, 1981), выражали в условных единицах.

Статистически значимыми считали отличия при $\mathrm{P}<0,05$ (использовали t-критерий Стьюдента после предварительной оценки нормальности распределения). На графиках представлены средние значения и стандартные ошибки ( $\pm \mathrm{SE})$.

\section{Результаты}

Индексы органов. За период наблюдений отмечены значительные колебания относительных масс органов у рыб, получивших инъекцию (рис. 1). Это, видимо, не позволило выявить статистически значимых отклонений от контроля. Однако можно проследить некоторые тенденции в динамике изменений параметра. Наиболее выраженные колебания показателя и рост ошибки средней вызвала инъекция масла.

У опытных рыб сразу после поступления токсиканта отмечен небольшой рост индексов селезенки, на 10-е сутки значения снизились и к концу эксперимента были минимальными относительно всех групп рыб за всю экспозицию. Гепатосоматические индексы снизились к концу опыта по сравнению с контролем как после инъекции масла, так и у опытных рыб. При этом у последних колебания показателя в течение эксперимента были более сильными, что свидетельствует об отклонениях в функциональном состоянии печени под действием арохлора.

Общий белок сыворотки крови. Наибольшие колебания уровня общего белка на начальном этапе наблюдений вызвала также инъекция масла, превышение значений показателя у рыб II группы на 3-10-е сутки было статистически значимым (рис. 2). Изменения данного параметра у опытных рыб в эти сроки были не такими резкими, однако к концу эксперимента концентрация сывороточного белка достоверно снизилась относительно контроля.

Гемоглобин. Резких колебаний концентрации гемоглобина, в отличие от других показателей, после инъекции масла не отмечено (рис. 3). У опытных рыб динамика изменений показателя 
была более выраженной: постепенный подъем, достижение максимума на 10-е сут и достоверное снижение к концу опыта.
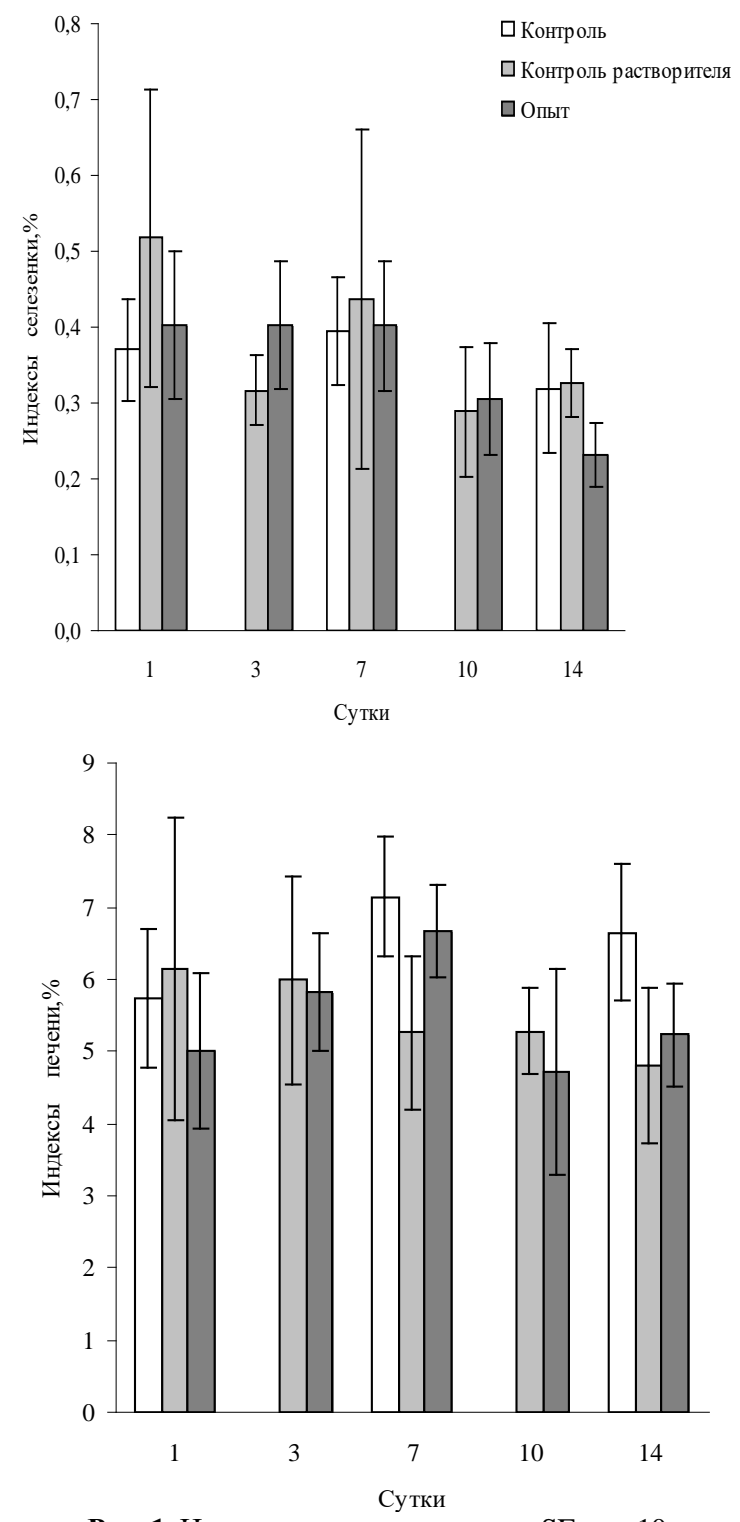

Рис. 1. Индексы органов карпа: $\mathrm{x} \pm \mathrm{SE}, \mathrm{n}=10$

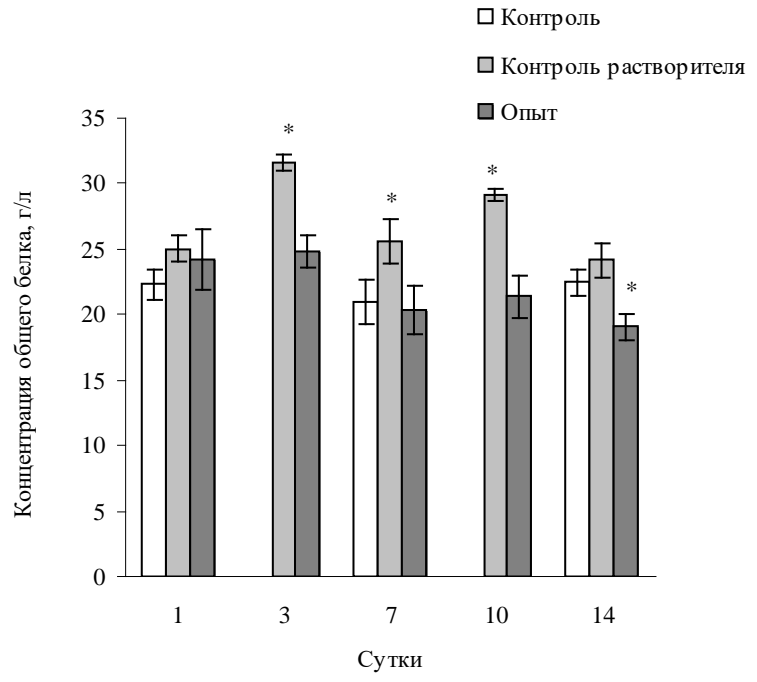

Рис. 2. Концентрация общего белка сыворотки крови карпа: $\mathrm{x} \pm \mathrm{SE}, \mathrm{n}=10$; - - значения, достоверно отличающиеся от контроля при $\mathrm{P}<0,05$
Циркулирующие иммунные комплексы. Довольно низкие значения показателя у всех подопытных рыб в нашем эксперименте объясняются, видимо, тем, что в период акклимации они находились при низком уровне антигенной нагрузки. В начале опыта уровень ЦИК у рыб II и III групп достоверно снизился (рис. 4), начиная с 7-х суток можно говорить о реакции именно на арохлор: у опытных рыб происходит резкий рост и затем снижение показателя, ставшее к концу опыта статистически достоверным.

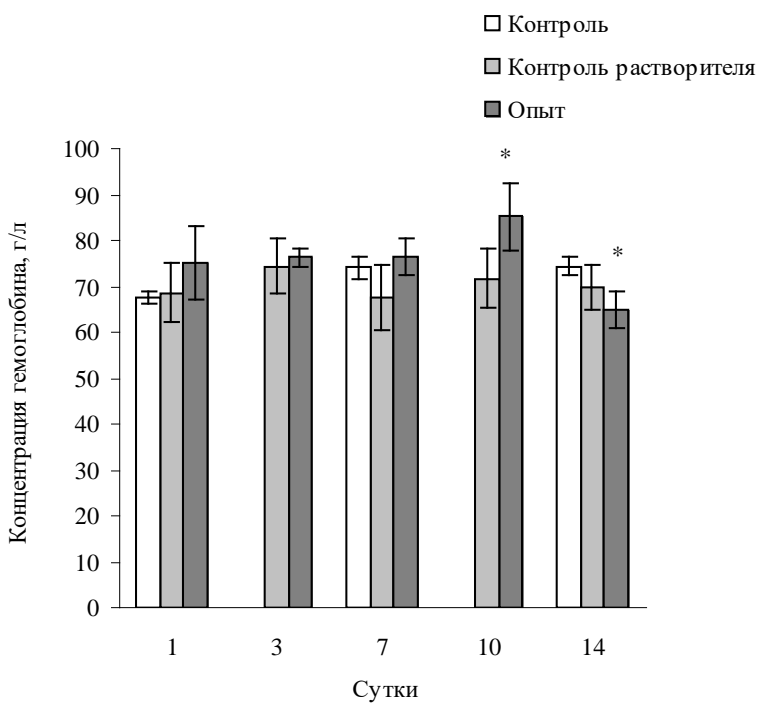

Рис. 3. Концентрация гемоглобина крови карпа: обозначения см. рис. 2

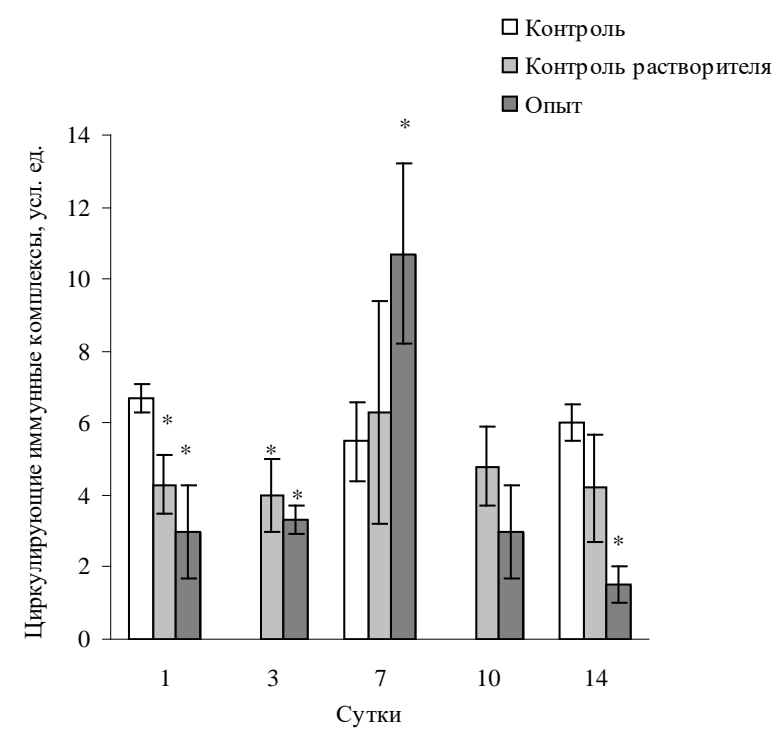

Рис. 4. Содержание ЦИК в сыворотке крови карпа: обозначения см. рис. 2

Глюкоза. В первый срок отбора у рыб II и III групп выявлен статистически значимый рост уровня гликемии (рис. 5). Далее содержание глюкозы нормализуется, однако у рыб опытной группы на 14-е сут показатель вновь значительно вырос.

\section{Обсуждение}

При анализе полученных данных обращает на себя внимание тот факт, что по большинству исследуемых показателей отмечали сдвиги на начальных этапах эксперимента как у опытных рыб, так и рыб II группы. Поскольку манипуляционный стресс в значительной степени был снят анестезией, можно заключить, что введение масла является возмущающим фактором, вызывающим развитие неспецифической стрессовой реакции. 
Динамика изменений индексов селезенки указывает на то, что в ответ на стрессовое воздействие, а именно инъекцию (рыбы II и III групп), происходит усиление кровенаполнения органа с последующей активизацией выхода эритроцитов в кровяное русло. Это необходимо для доставки дополнительного кислорода к тканям и органам, работающим в условиях повышенной нагрузки. У рыб II группы далее наступает фаза адаптации, и показатель возвращается на уровень, близкий к контрольному.

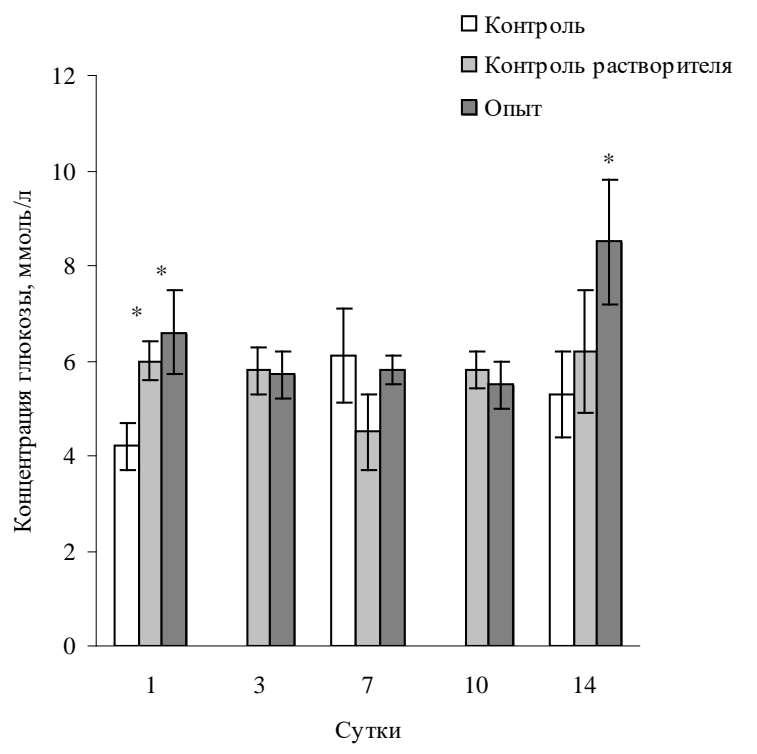

Рис. 5. Концентрация глюкозы крови карпа: обозначения см. рис. 2

У опытных рыб потребность в переносе повышенного количества кислорода для обеспечения процессов нейтрализации и выведения метаболитов Арохлора и, соответственно, в большем поступлении эритроцитов в кровоток, сохраняется. Токсическое действие, которое вызывают ПХБ на многие внутренние органы, и в том числе на селезенку (Monosson, 1999), способно нарушить функции органа, в том числе вызвать угнетение гемопоэза. Селезенка не в состоянии вырабатывать достаточного количества эритроцитов для компенсации вышедших из депо клеток, что приводит к снижению относительной массы органа у опытных рыб к концу эксперимента.

Данное положение подтверждается динамикой изменений уровня гемоглобина. Инъекция сама по себе, как стрессовый фактор, не оказала заметного влияния на показатель в первые 7 суток. Однако к 10-м суткам у опытных рыб концентрация гемоглобина статистически значимо превысила контрольный уровень, что является результатом усиленного выхода депонированных в селезенке эритроцитов. Далее, к концу эксперимента, за счет снижения количества эритроцитов, поступающих в кровяное русло, содержание гемоглобина снижается.

Аналогичная динамика изменений показателя выявлена при действии на рыб широкого ряда токсикантов (Kori-Siakpere et al., 2005, 2007; Saglam, 2008; Moiseenko, 2009). Достоверное снижение уровня гемоглобина является признаком анемии, причиной которой могут быть разрушение эритроцитов или снижение их выработки, гемодилюция и т. д. (Sawhney and Johal, 2000; Patnaik and Patra, 2006). Кроме анемии, нарушения синтеза гемоглобина у рыб под воздействием ПХБ и ряда других антропогенных загрязнений, возможно также излишнее отложение гемосидерина (Khan and Nag, 1993), что свидетельствует о нарушениях в системе крови.

Наиболее чувствительным к химическому загрязнению органом является печень, что обусловлено ее исключительно важной ролью в метаболических и детоксикационных процесcax (Ayas, 2007). Гепатосоматический индекс является одним из показателей состояния обмена веществ у рыб. Его увели- чение обычно связывают с усиленной детоксикационной активностью в ответ на поступление токсических соединений (Pereira and Kuch, 2005). Однако приводятся сведения о том, что снижение данного параметра также является показателем наличия химического стресса (Kopecka et al., 2006). Поскольку у рыб печень является и основным органом синтеза сывороточных белков, любое токсическое воздействие, нарушая нормальное функционирование органа, не может не влиять на уровень этого важнейшего показателя.

Полученная нами картина изменений содержания общего белка сыворотки крови является неспецифической и отмечается при действии токсических факторов различной природы (Borges et al., 2003; Lapirova and Mikryakov, 2005; Öner et al., 2008). Некоторый рост уровня показателя в начале воздействия часто вызван усилением синтеза защитных факторов белковой природы в ответ на стресс, что и наблюдается у рыб II и III групп, получивших инъекцию. Дальнейшее снижение содержания сывороточного белка у опытных рыб может быть обусловлено влиянием токсиканта или продуктов его трансформации на печень и почки, что вызывает нарушение белкового обмена, а также усиленным образованием липопротеинов, необходимых для восстановления поврежденных клеточных и тканевых органелл, что было выявлено и при действии ряда других ксенобиотиков (Ghosh and Chatterjee, 1989; AlAkel et al., 2010).

У низших позвоночных, в том числе рыб, вследствие более слабого развития специфического (приобретенного) иммунитета, приоритетная роль принадлежит факторам неспецифического (врожденного) иммунитета (Magnadottir, 2006). Огромное значение в обеспечении иммунного гомеостаза организма имеет противомикробная активность сыворотки крови, которая обусловлена наличием в ней комплемента, интерферона, трансферрина, лизоцима и других соединений (Bayne and Gerwick, 2001; Ellis, 2001; Saurabh and Sahoo, 2008). В основном эти вещества имеют белковую природу, поэтому некоторые исследователи относят уровень сывороточного белка к элементам неспецифической иммунной системы (Jeney et al., 1997). Снижение показателя, выявленное в конце экспозиции у опытных рыб, позволяет предположить ослабление гуморального звена неспецифического иммунитета под действием токсиканта, и, соответственно, снижение общей резистентности. В целом при оценке физиологического статуса животных снижение концентрации сывороточного белка ниже референсных значений относят к неблагоприятным признакам.

В сыворотке крови человека и животных также постоянно присутствуют иммунные комплексы (комплексы «антиген антитело»), являющиеся важной составляющей механизма поддержания иммунного гомеостаза. Уровень показателя определяется условиями существования рыб, элиминация образовавшихся ЦИК производится клетками ретикулоэндотелиальной системы (РЭС) (Levinsky, 1981).

Достоверное снижение уровня ЦИК у рыб II и III групп в начале опыта является, скорее всего, результатом мобилизации ресурсов неспецифической защиты в ответ на инъекцию и активизацией механизмов выведения чужеродного материала. Можно предположить, что к 7-м суткам в процессе трансформации Арохлора образуется максимальное количество метаболитов, которые связываются антителами с последующим выведением образовавшихся ЦИК из кровяного русла. Резкое снижение ЦИК в конце опыта может быть обусловлено либо ускоренным выведением ЦИК из циркуляции вследствие работы РЭС в форсированном режиме, либо недостаточным поступлением антител из-за сбоев в функционировании механизмов неспецифической защиты, вызванных токсикантом.

Глюкоза входит в число основных характеристик физиологического состояния животных. Объясняется это тем, что она играет важнейшую роль в обеспечении организма энергией (Polakof et al., 2012). С другой стороны, содержание глюкозы в крови может быть индикатором воздействия неблагоприятных 
факторов любой природы. Как и у высших позвоночных, у рыб стресс инициирует выброс глюкокортикоидов и катехоламинов (Hontela et al., 1996; Ricard et al., 1998). Эти гормоны могут вызывать усиление процессов гликогенолиза, повышение активности глюкозо-6-фосфатазы в печени (Vijayram et al., 1989; Iwama, 1999; Almeida et al., 2001), а также инициировать глюконеогенез (Sastry and Shukla, 1994; Mini, 2015). В результате на начальных этапах воздействия, в том числе токсического, у рыб, как правило, отмечают рост уровня гликемии (Cicik and Engin, 2005; Sepici-Dinçel et al., 2009; Authman et al., 2015). Результаты нашего эксперимента подтверждают это положение, у рыб, получивших инъекцию, в первые сутки значения содержание глюкозы достоверно превышено. Затем наступает фаза адаптации именно к этому воздействию и показатель у всех подопытных рыб выравнивается. Но, как и в случае остальных исследованных биохимических параметров, к концу эксперимента уровень гликемии резко повышается, что может указывать на активизацию процессов детоксикации Арохлора или его метаболитов и, соответственно, возрастание энергетических затрат организма. Для компенсации этих затрат вновь включаются механизмы высвобождения глюкозы как наиболее легко доступного энергетического ресурса.

\section{Заключение}

Внутрибрюшинное введение масла вне зависимости от того, содержит оно токсикант или нет, оказывает раздражающее действие, вызывая у рыб на начальных этапах экспозиции развитие общей неспецифической стрессовой реакции. Инициировать ее могут неблагоприятные факторы различной природы, характерными признаками являются фазовые колебания показателей, а также рост их индивидуальной изменчивости, что и наблюдалось у рыб II и ІІІ групп по сравнению с интактными особями.

Далее реакция на стресс выходит на стадию адаптации, и у рыб II группы значения исследуемых показателей до конца эксперимента не значительно отличаются от контрольных. Резкое повышение уровня ЦИК на 7-е сутки у опытных рыб свидетельствует о росте антигенной нагрузки, картина динамики всех биохимических показателей указывает на то, что на 10-14-е сутки наиболее активно происходят процессы детоксикации и выведения Арохлора и продуктов его трансформации, которые требуют повышенных затрат кислорода и энергии. Но, поскольку нормальное функционирование внутренних органов (почки, селезенка, печень) нарушено вследствие токсического действия Арохлора, происходят сдвиги в процессах гемопоэза, белковом и углеводном обмене. В условиях повышенной нагрузки функционируют клетки РЭС, ответственные за элиминацию чужеродного материала.

Учитывая разовое поступление токсиканта и степень отклонения исследованных показателей, можно предположить, что в результате адаптационных процессов далее возможен выход всех параметров на уровень, близкий к контрольным значениям.

Автор выражает глубокую благодарность заведующему лабораторией физиологии и токсикологии водных животных ИБВВ РАН Г. М. Чуйко и сотрудникам Е. А. Заботкиной, В. В. Юрченко и другим за помощь в получении материала для исследования.

\section{References}

Al-Akel, A. S., Alkahem-Al-Balawi, H. F., Al-Misned, F., Mahboob, S., Ahmad, Z., \& Suliman, E. M. (2010). Effects of dietary copper exposure on accumulation, growth, and hematological parameters in Cyprinus carpio. Toxicological and Environmental Chemistry, 92, 1865-1878.

Alexander, J. B., \& Ingram, J. A. (1992). Noncellular nonspecific defense mechanisms of fish. Annual Review of Fish Diseases, 2, 249-279.
Almeida, J. A., Novelli, E. L. B., Dal-Pai Silva, M., \& Alves-Junior, R. (2001). Environmental cadmium exposure and metabolic responses of the Nile tilapia Oreochromis niloticus. Environmental Pollution, 114, 169-175.

Arkoosh, M. R., Clemons, E., Huffman, P., Kagley, A. N., Casillas, E., \& Adams, N. (2011). Increased susceptibility of juvenile Chinook salmon to vibriosis after exposure to chlorinated and aromatic compounds found in contaminated urban estuaries. Journal of Aquatic Animal Health, 13, 257-268.

Arruda, A. F., Goicoechea, H. C., Santos, M. C., \& Olivieri, A. C. (2003). Solidliquid extraction room temperature phosphorimetry and pattern recognition for screening polycyclic aromatic hydrocarbons and polychlorinated biphenyls in water samples. Environmental Science and Technology, 37(7), 1385-1391.

Ayas, Z., Ekmekci, G., Ozmen, M., \& Yerli, S. V. (2007). Histopathological changes in the livers and kidneys of fish in Sariyar Reservoir, Turkey. Environmental Toxicology and Pharmacology, 23(2), 242-249.

Barnthouse, L. W., Glaser, D., \& DeSantis, L. (2009). Polychlorinated biphenyls and Hudson River white perch: Implications for population-level ecological risk assessment and risk management. Integrated Environmental Assessment and Management, 5(3), 435-444.

Bayne, C. J., \& Gerwick, L. (2001). The acute phase response and innate immunity of fish. Developmental and Comparative Immunology, 25, 725-743.

Borges, A., Scotti, L. V., Siqueira, D. R., Zanini, R., Amaral, F. D., Jurinitz, D. F., \& Wassermann, G. F. (2007). Changes in hematological and serum biochemical values in jundiá Rhamdia quelen due to sub-lethal toxicity of cypermethrin. Chemosphere, 69, 920-926.

Bradford, M. M. (1976). A rapid and sensitive method for the quantitation of microgram quantities of protein utilizing the principal of protein dye binding. Analytical Biochemistry, 72, 248-254.

Cicik, B., \& Engin, K. (2005). The effects of cadmium on levels of glucose in serum and glycogen reserves in the liver and muscle tissues of Cyprinus carpio (L., 1758). Turkish Journal Veterinary and Animal Sciences, 29, 113-117.

Ellis, A. E. (2001). Innate host defense mechanism of fish against viruses and bacteria. Developmental and Comparative Immunology, 25, 827-839.

Fedorov, L. A. (1993). Dioksiny kak ehkologicheskaya opasnost': Retrospektiva i perspektivy [Dioxins as ecological hazard: Retrospective and prospects]. Nauka, Moscow (in Russian).

Ghosh, T. K., \& Chatterjee, S. K. (1989). Influence of nuvan on the organic reserves of Indian freshwater murrel Channa punctatus. Journal of Environmental Biology, 10, 93-99.

Gorbunova, T. I., Pervova, M. G., Zabelina, O. N., Saloutin, V. I., \& Chupahin, O. N. (2011). Polihlorbifenily: Problemy ehkologii, analiza i himicheskoj utilizacii [Polychlorinated biphenyls: Environmental issues, analysis, and chemical disposal], Krasand, Moscow; UrO RAN, Ekaterinburg (in Russian).

Grinevich, Y. A., \& Alferov, A. N. (1981). Opredelenie immunnyh kompleksov v krovi onkologicheskih bol'nyh [Determination of immune complexes in the blood of cancer patients]. Laboratornoe Delo, 8, 493-496 (in Russian).

Henry, T. B. (2015). Ecotoxicology of polychlorinated biphenyls in fish A critical review. Critical Reviews in Toxicology, 45(8), 643-661.

Iwama, G. K., Vijayan, M. M., Forsyth, R. B., \& Ackerman, P. A. (1999). Heat shock proteins and physiological in fish. American Zoologyst, 39, 901-909.

Iwanowicz, L. R., Blazer, V. S., McCormick, S. D., Vanveld, P. A., \& Ottinger, C. A. (2009). Aroclor 1248 exposure leads to immunomodulation, decreased disease resistance and endocrine disruption in the brown bullhead, Ameiurus nebulosus. Aquatic Toxicology, 93, 70-82.

Jeney, G., Galeotti, M., Volpatti, D., Jeney, Z., \& Anderson, D. P. (1997). Prevention of stress in rainbow trout (Oncorhynchus mykiss) fed diets containing different doses of glucan. Aquaculture, 154, 1-15.

Khan, R. A. (2003). Health of flatfish from localities in Placentia Bay, Newfoundland, contaminated with petroleum and PCBs. Archives of Environmental Contamination and Toxicology, 44(4), 485-492.

Khan, R. A., \& Nag, K. (1993). Estimation of hemosiderosis in seabirds and fish exposed to petroleum. Bulletin of Environmental Contamination and Toxicology, 51, 125-131.

Kopecka, J., Lehtonen, K., Barsiene, J., Broeg, K., Vuorinen, P., Gercken, J., \& Pempkowiak, J. (2006). Overview of biomarker responses in fish (Platichthys flesus) and mussels (Mytilus trossulus) from the Gdansk Bay. Marine Pollution Bulletin, 53, 406-421.

Kori-Siakpere, O., Adamu, K. M., \& Madukelum, I. T. (2007). Acute haematological effects of sublethal levels of paraquat on the African Catfish, Clarias gariepinus (Osteichthyes: Clariidae). Research Journal of Environmental Sciences, 1, 331-335.

Kori-Siakpere, O., Ake, J. E. G., \& Avworo, U. M. (2005). Sublethal effects of cadmium on some selected haematological parameters of heteroclarias (a hybrid of Heterobranchus bidorsalis and Clarias gariepinus). International Journal of Zoological Research, 2, 77-83.

Lapirova, T. B., \& Mikryakov, V. R. (2005). Vliyanie nekotoryh stress-faktorov na funkcional'noe sostoyanie gumoral'nogo zvena nespecificheskogo immuniteta molodi karpa [Influence of some stress factors on the functional 
state of a humoral link of nonspecific immunity of juvenile fish carp]. Voprosy Rybolovstva, 6(4), 771-780 (in Russian).

Levinsky, R. (1981). Role of circulating immune complexes in renal diseases. Journal of Clinical Pathology, 34, 1214-1222.

Magnadottir, B. (2006). Innate immunity of fish (overview). Fish and Shellfish Immunology, 20, 137-151.

Moiseenko, T. I. (2009). Vodnaya ehkotoksikologiya: Teoreticheskie i prikladnye aspekty [Aquatic ecotoxicology: Theoretical and applied aspects]. Nauka, Moscow (in Russian).

Monosson, E. (1999). Reproductive and developmental effects of PCBs in fish: Summary of laboratory and field studies. Reviews of Toxicology, 3, 25-75.

O’Neil, J. A., \& Johnson, T. B. (2013). Validation of rapid assimilation of PCBs following IP dosing in the Round Goby (Neogobius melanostomus). Bulletin of Environmental Contamination and Toxicology, 91, 135-140.

Öner, M., Atli, G., \& Canli, M. (2008). Changes in serum biochemical parameters of freshwater fish Oreochromis niloticus following prolonged metal (Ag, Cd, $\mathrm{Cr}, \mathrm{Cu}, \mathrm{Zn}$ ) exposures. Environmental Toxicology and Chemistry, 27, 360-366.

Pääkkönen, J.-P. J., Rantalainen, A.-L., Karels, A., Nikkilä, A., \& Karjalainen, J. (2005). Bioaccumulation of PCBs in burbot (Lota lota L.) after delivery in natural food. Archives of Environmental Contamination and Toxicology, 49(2), 223-231.

Patnaik, L., \& Patra, A. K. (2006). Haematopoietic alterations induced by carbaryl in Clarias batrachus (Linn.). Journal of Applied Sciences and Environmental Management, 10, 5-7.

Pereira, M. S., \& Kuch, B. (2005). Heavy metals, PCDD/F and PCB in sewage sludge samples from two wastewater treatment facilities in Rio de Janeiro State, Brazil. Chemosphere, 60(7), 844-853.
Polakof, S., Panserat, S., Soengas, J. L., \& Moon, T. W. (2012). Glucose metabolism in fish: A review. Joumal of Comparative Physiology B, 182, 1015-1045.

Quabius, E., Nolan, D., Segner, H., \& Bonga, S. E. W. (2002). Confinement stress and starvation modulate the induction of EROD activity after dietary exposure to PCB 126 in the Mozambique tilapia (Oreochromis mossambicus). Fish Physiology and Biochemistry, 25, 109-119.

Rodenburg, L. A., Du, S., Fennell, D. E., \& Cavallo, G. J. (2010). Evidence for widespread dechlorination of polychlorinated biphenyls in groundwater, landfills, and wastewater collection systems. Environmental Science and Technology, 44, 7534-7540.

Safe, S. H. (1994). Polychlorinated biphenils (PBCs): Environmental impact, biochemical and toxic responses, and implications for risk assessment. Critical Reviews in Toxicology, 24, 87-149.

Saglam, N. (2009). Effects of sulfamerazine on selected haematological and immunological parameters in rainbow trout (Onchorhynchus myriss, Walbaum, 1792). Aquaculture Research, 40(4), 395-404.

Sawhney, A. K., \& Johal, M. S. (2000). Erythrocyte alterations induced by malathion in Channa punctatus (Bloch). Bulletin of Environmental Contamination and Toxicology, 64, 398-405.

Sepici-Dinçel, A., Benli, A. Ç. K., Selvi, M., Sarıkaya, R., Sahin, D., Özkul, I. A., \& Erkoç, F. (2009). Sublethal cyfluthrin toxicity to carp (Cyprinus carpio L.) fingerlings: Biochemical, hematological, histopathological alterations. Ecotoxicology and Environmental Safety, 72, 1433-1439.

Winkaler, E. U., Santosh, T. R. M., Machdo-Neto, J. G., \& Martinez, C. B. R. (2007). Acute lethal and sub-lethal effects of neem leaf extracts on neotropical freshwater fish, Prochilodus lineatus. Comparative Biochemistry and Physiology. Part C, 145, 236-244. 